\title{
Resistência, inovação e clínica no pensar e no agir de Nise da Silveira
}

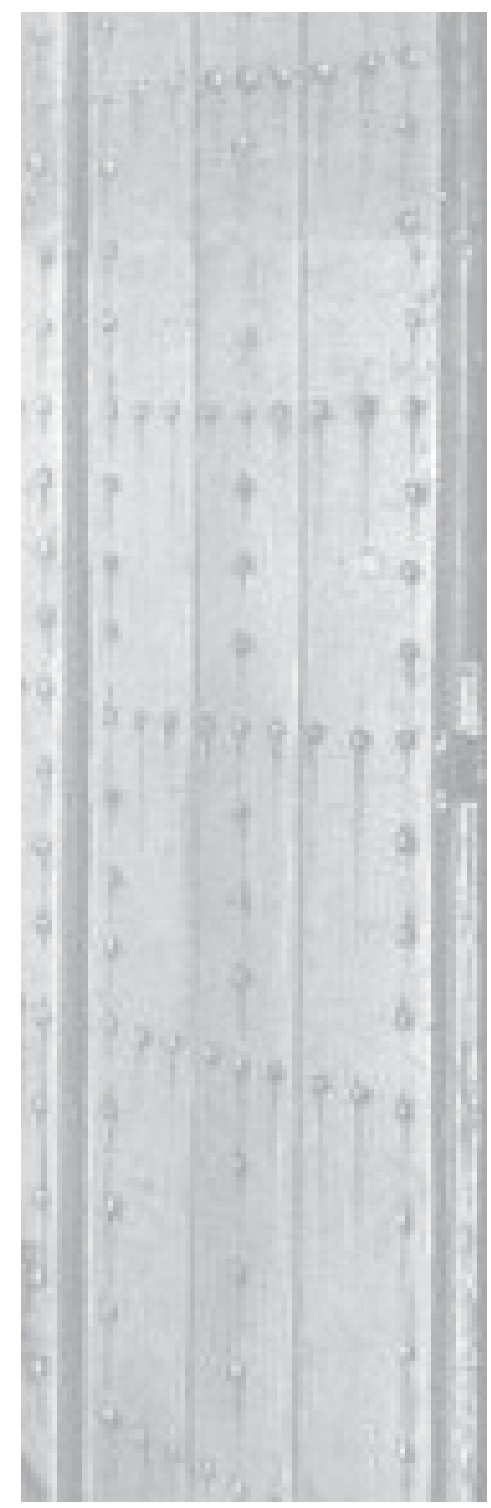

Eliane Dias de Castro ${ }^{1}$ Elizabeth Maria Freire de Araújo Lima²

Introdução

No decorrer da década de 1940, a psiquiatria hegemônica brasileira se voltou para inovações científicas e tecnológicas, tais como eletrochoques e cirurgias neurológicas, e para a sedimentação de uma visão orgânica de doença mental que abriria caminho para o incremento dos neurolépticos uma década depois. Nesse contexto, uma médica psiquiatra, movida pela força de sua indignação com o tratamento oferecido aos pacientes dos hospitais psiquiátricos, e pela "aposta de que lá onde eram jogados os rebotalhos da sociedade utilitarista, havia sujeitos" (Quinet, 2000, p.209), investiu na pesquisa e no desenvolvimento de uma prática clínica em terapia ocupacional. Para ela, esse investimento era parte de uma preocupação com os rumos que a psiquiatria vinha tomando, e estava vinculado ao compromisso de criar procedimentos terapêuticos de caráter humanista para o tratamento da esquizofrenia.

É esta aventura intelectual e sensível, das mais belas e potentes desenvolvidas no Brasil, que buscaremos apresentar e analisar aqui, e que se constituiu numa experiência ímpar na arte, psiquiatria e terapia ocupacional brasileiras. O presente trabalho é um desdobramento de estudos históricos e teóricos realizados e atualizados na compreensão de situações clínicas de terapia ocupacional, que são realizadas na interface da arte e promoção da saúde, e configura-se como uma homenagem a Nise da Silveira, no aniversário de seu centenário.

\footnotetext{
1 Terapeuta ocupacional; doutora em Ciências da Comunicação; pós-doutoranda, Laboratório de Estudos em Psicologia da Arte, Instituto de Psicologia, Universidade de São Paulo; professora, Curso de Terapia Ocupacional, Faculdade de Medicina, Universidade de São Paulo. São Paulo, SP. <elidca@usp.br>

${ }^{2}$ Terapeuta ocupacional; doutora em Psicologia Clínica; pós-doutoranda, Núcleo de Estudos da Subjetividade, Programa de Estudos Pós-Graduados em Psicologia Clínica, Pontifícia Universidade Católica de São Paulo; professora, Curso de Terapia Ocupacional, Faculdade de Medicina, Universidade de São Paulo. São Paulo, SP. <beth.lima@usp.br>
} 


\section{A organização do Setor de Terapêutica Ocupacional}

Em meados da década de 1940, quando Nise da Silveira iniciou seu trabalho no Centro Psiquiátrico Nacional - hoje Centro Psiquiátrico Pedro II, do Rio de Janeiro -, a polarização que existia nas primeiras décadas do século, e que dividia a psiquiatria entre as práticas ergoterápicas e o desenvolvimento de bases científicas e orgânicas, se havia desfeito. A ergoterapia fora condenada ao limbo e as práticas correntes baseavam-se em eletrochoques, lobotomias e, posteriormente, em terapia química e medicamentosa. Nise opôs-se frontalmente a tais procedimentos, colocou-se desde o início num embate contra a psiquiatria de seu tempo. Para ela, a vida psíquica deveria ser pensada como processo constante de interação com aquilo que cerca cada ser humano. A psicopatologia, numa dimensão fenomenológica, consistiria em planos de experiência, em modos de existência e de estar no mundo. Seu interesse era penetrar no mundo interno dos esquizofrênicos, aproximar-se deles, conhecer-lhes a dor e, ao mesmo tempo, melhorar suas condições de vida. Para isso, passou a gerenciar um setor sem recursos no Centro Psiquiátrico Nacional, o Setor de Terapêutica Ocupacional, considerado, na época, um método destinado a apenas 'distrair' ou contribuir com a economia hospitalar.

Para enfrentar a psiquiatria, seguiu este outro caminho, o da Terapêutica Ocupacional e, para sustentar essa opção, Nise se propôs a fortalecer esse método e dar-lhe fundamentação científica, transformando-o em um campo de pesquisa. Assim, buscou construir uma terapêutica ocupacional com características científicas, imprimindo ao trabalho uma orientação própria: sua preocupação era de natureza teórica e clínica. Durante os 28 anos em que dirigiu o Setor de Terapêutica Ocupacional e Reabilitação (STOR) no Centro Psiquiátrico Pedro II (1946-1974), diversas pesquisas foram desenvolvidas com o intuito, entre outros, de: registrar os resultados obtidos com a utilização de atividades; comprovar a eficácia dessa forma de tratamento; investigar efeitos nocivos dos tratamentos psiquiátricos tradicionais; comprovar capacidades criativas e de aprendizado dos esquizofrênicos. Nesse período, foram desenvolvidos, progressivamente, dezessete núcleos de atividades: encadernação, marcenaria, trabalhos manuais, costura, música, dança, teatro, etc., nos quais procuravam-se oferecer atividades que estimulassem o fortalecimento do ego dos pacientes, a progressiva ampliação do relacionamento com o meio social, e que servissem como meio de expressão. Nise acreditava que "se houver um alto grau de crispação da consciência, muitas vezes, só as mãos são capazes de fantasia" (Jung apud Silveira, 1981, p.102).

Nos atendimentos que realizava, Nise procurava criar um clima de liberdade, sem coação, no qual, por meio de diversas atividades, os sintomas pudessem encontrar oportunidade para sua expressão e, como ela dizia, serem despotencializados. Para ela: "o exercício de múltiplas atividades ocupacionais revelava que o mundo interno do psicótico encerra insuspeitadas riquezas e as conserva mesmo depois de longos anos de doença, contrariando conceitos estabelecidos" (Silveira, 1981, p.11).

O Centro Psiquiátrico tinha 1.500 pacientes hospitalizados, normalmente abandonados no pátio do hospital. Os ateliês atraíam, para seus setores, pessoas com uma experiência cotidiana de uma vida vazia e sem sentido. Era o início de uma luta por uma série de transformações no ambiente hospitalar e nas formas de tratamento dos pacientes. Nise afirmava que o hospital colaborava com a doença e acreditava que caberia à terapêutica ocupacional parte importante na mudança desse ambiente. O número de pacientes que freqüentavam o setor era reduzido, devido talvez "a não aceitação pelos psiquiatras das ocupações como agentes terapêuticos" (Silveira, 1981, p.24).

A articulação entre o STOR e os outros serviços médicos era tênue: os psiquiatras não indicavam a seus pacientes esse tratamento e aqueles que vinham ao Setor o faziam por iniciativa própria ou por serem convidados por algum monitor. O desinteresse por parte da psiquiatria teria sido, também, responsável pelo fechamento de várias oficinas. 


\section{Do ateliê de pintura ao museu de imagens do inconsciente}

Entre os vários núcleos de atividade, havia o ateliê de pintura. Segundo Mavignier (2000), que a essa época trabalhava em um setor administrativo do Hospital, foi em uma exposição de trabalhos manuais do STOR que ele propôs a Nise da Silveira a organização de um ateliê de pintura para os internos. Como a idéia vinha de encontro a um antigo projeto da doutora, Mavignier solicitou sua transferência para lá e, juntos, trabalharam no sentido de implementá-la. O Ateliê de Pintura cedo se destacou e adquiriu posição especial, passando a receber um investimento diferenciado por parte da psiquiatra. Nise afirmava que todas as atividades realizadas no Setor de Terapêutica Ocupacional eram expressivas, mas observou, nos freqüentadores do ateliê de pintura, "a existência de uma pulsão configuradora de imagens sobrevivendo mesmo quando a personalidade estava desagregada" (Silveira, 1992, p.63).

O acompanhamento dos ateliês de pintura e modelagem proporcionou a Nise uma maior compreensão do dinamismo psíquico presente na esquizofrenia e, também, reflexões constantes sobre as condições do tratamento psiquiátrico e da hospitalização. As dificuldades encontradas a conduziram a estudos apaixonantes, muitas vezes articulados a outros campos do conhecimento, como a arte, a psicologia, a mitologia e a literatura. Para ela, "a criatividade é o catalisador por excelência das aproximações de opostos. Por seu intermédio, sensações, emoções, pensamentos, são levados a reconhecerem-se entre si, a associarem-se, e mesmo tumultos internos adquirem forma" (Silveira, 1981, p.11).

Nise foi surpreendida pela quantidade de trabalhos produzidos e pela manifestação de criatividade que resultava na produção de pinturas em número incrivelmente grande, num contraste com a atividade reduzida de seus autores fora dos espaços de ateliê. A qualidade de muitos desenhos, pinturas e modelagens fascinavam e entusiasmavam a psiquiatra e o monitor do ateliê de pintura. Mavignier estava ali, segundo seu próprio relato, como pintor, e não como psiquiatra. Tinha interesse "nos artistas a descobrir, procurando-os nos pátios e nas enfermarias do hospital" (Mavignier, 2000, p.247).

Sua presença contribuía, também, para dar um caráter de verdadeiro ateliê de pintura ao espaço, colaborando com conhecimentos técnicos, sobre os materiais e com sua sensibilidade estética. Além disso, Mavignier teve um papel fundamental nos desdobramentos que o trabalho veio a ganhar, pois foi o primeiro elo entre a experiência no Engenho de Dentro e o grupo de artistas plásticos cariocas que, como ele, estavam se iniciando no campo das artes plásticas, entre eles, Abraham Palatnik e Ivan Serpa. Juntos montaram e ordenaram as primeiras séries de desenhos e pinturas.

A quantidade e qualidade dos trabalhos os levaram a organizar a primeira exposição dessas produções, em 1947, no Ministério da Educação, no Rio de Janeiro. Mário Pedrosa, que visitou e escreveu sobre essa exposição, passou, a partir daí, a freqüentar o ateliê de pintura. Em 1949, o crítico levou Leon Degand, então diretor do Museu de Arte Moderna de São Paulo, que ficou impressionado com os trabalhos produzidos e propôs a realização de uma mostra destes no Museu que dirigia. "Era uma tentativa para entrar em contato com pessoas talvez interessadas pelo apaixonante problema que nos empolgava" (Silveira, 1981, p.14).

É importante salientar que os críticos de arte mostraram-se muito mais atentos ao fenômeno da produção plástica dos internos do Engenho de Dentro que os psiquiatras brasileiros, inicialmente os interlocutores que Nise buscava alcançar. Mais que isso, a doutora chamava a atenção para o fato de que os psiquiatras, em sua grande maioria, se recusavam a aceitar qualquer valor artístico de trabalhos plásticos realizados por doentes mentais, insistindo na idéia de "arte psicopatológica", procurando neles apenas sintomas e reflexo de ruína psíquica. É fato que Nise manteve, sempre, certa discrição quanto a se posicionar sobre a qualidade estética dos trabalhos produzidos no ateliê, deixando essa 
tarefa para os críticos e dedicando-se ao estudo científico dos problemas que essa produção levantava. No entanto, a possibilidade de que entre seus pacientes houvesse aqueles com capacidades artísticas era vista por ela com naturalidade:

\author{
Haverá doentes artistas e não artistas, assim como, entre os indivíduos que \\ se mantêm dentro das imprecisas fronteiras da normalidade, só alguns \\ possuem a força de criar formas dotadas do poder de suscitar emoções \\ naqueles que as contemplam (Silveira apud Gullar, 1996, p.96).
}

Após as primeiras exposições, e como a produção do ateliê de pintura aumentava a cada dia, foi criado o Museu de Imagens do Inconsciente, com o intuito de organizar e catalogar esse material, com critério e cautela - o que permitiria o desenvolvimento de uma série de pesquisas em torno dessas imagens, levando à organização dessas produções. Num gesto inédito para a cultura brasileira, envolvendo artistas e críticos de arte nesse processo, Nise recorre a um tratamento museográfico das obras dos pacientes. Mantendose sempre no campo da psiquiatria, Nise não deixou de buscar parcerias no campo das artes. Demonstrando uma excepcional capacidade de articulação entre campos de conhecimento, desde o início propôs que o Museu pudesse se tornar um Centro de Estudo aberto não só a psiquiatras, mas também a antropólogos, artistas, críticos de arte interessados pela atividade criadora. Podemos pensar que mesmo a idéia de criação de um museu vem da contaminação pelo campo da arte. Estávamos, de fato, num momento de fermentação estética, que culminou com aquilo que Mário Pedrosa chamou de "a moda dos museus": o Museu de Arte de São Paulo foi criado em 1947, o de Arte Moderna em 1948, o MAM, do Rio, em 1949, e a primeira Bienal foi realizada em 1951 (Pedrosa, 1995).

Nise convidava profissionais de outras áreas para participar do trabalho prático no ateliê, configurando uma proposta de caráter interdisciplinar. Para ela, estudos da arte, dos mitos, religiões, literatura, possibilitam contato com formas de expressão das mais profundas emoções humanas (Silveira, 1981).

Essas parcerias conectavam os trabalhos realizados nos ateliês ao mundo das artes, possibilitando que outros olhares viessem banhá-los de outros significados, tornando visíveis traços e linguagens que escapam ao olhar do especialista médico. Mas o Museu não tinha só o objetivo de organização de acervo. Enquanto a experiência nos ateliês do Setor de Terapêutica Ocupacional foi se tornando conhecida nos meios artísticos, Nise da Silveira e sua equipe se deparavam com problemas cada vez mais complexos: como ajudar os artistas revelados no Engenho de Dentro, propiciando-Ihes um futuro menos trágico e, ao mesmo tempo, preservar suas obras? O Museu assim criado teria de ser, também, um abrigo e completar-se numa comunidade.

Assim, se no curso do seu desenvolvimento esse Museu acabou por se tornar um museu híbrido, podendo ser considerado também um Museu de Arte, seu surgimento esteve ligado a um interesse científico, clínico, e artístico, pelas produções e seus produtores. Além da criação do Museu, as exposições dos trabalhos produzidos nos ateliês do Engenho de Dentro tornaram-se freqüentes em reuniões e Congressos de psiquiatria, e também em espaços dedicados a arte: no MASP, em São Paulo, em Paris, Zurique, Roma, etc., sempre atraindo grande número de visitantes. Obras e artistas foram, aos poucos, se desprendendo de sua origem e vínculo com uma instituição psiquiátrica, para fazer seu percurso no universo cultural, como podemos perceber ao ler os depoimentos dos visitantes da Exposição de Arte Incomum, na XVI Bienal de São Paulo, e ver de que forma aquelas obras passaram a afetar o público (Frayze-Pereira, 1995).

Essas exposições tinham o poder de interpelar seus visitantes, levando-os a se perguntarem: como loucos, relegados a uma vida restrita, internados em grandes asilos, podiam produzir trabalhos tão belos? Para Nise, havia uma resposta: 
porque as vivências sofridas pelos pacientes, bem como as riquezas de seu mundo interior, invisíveis para aqueles que se detêm apenas na miséria de seu aspecto externo, (...) apontam para a necessidade de uma reformulação da atitude face a esses doentes e de uma radical mudança nos tristes lugares que são os hospitais psiquiátricos.. (Silveira, 1992, p.18)

Assim, os trabalhos produzidos nos ateliês e suas exposições eram também armas de combate ao manicômio e ao tratamento psiquiátrico hegemônico, aliadas na luta pela transformação cultural de certa concepção de loucura e do enlouquecimento.

As exposições das obras do acervo do Museu mostraram-se uma estratégia de agenciar essas produções, fazê-las entrar no circuito da produção cultural, transformando pacientes psiquiátricos em artistas - a produção artística que emergia pode ser compreendida como fato de cultura. Hoje, o Museu tem em torno de 350 mil obras, que habitam uma apertada reserva técnica; é referência internacional e fundamental na revelação humana dos "estados perigosos do ser"; desempenha um papel importante na transformação cultural em direção a uma sociedade mais tolerante, que pode se enriquecer com suas diferenças.

Para Nélson Aguilar, o Museu de Imagens do Inconsciente é uma espécie de produto da arte moderna e, entre os institutos afins, é o que tem o mais longevo e bem sucedido acervo criado com base em um programa de terapia ocupacional (Aguilar apud Cancino, 1999).

\section{Teoria e clínica na terapêutica ocupacional de Nise}

Em 1966, Nise da Silveira publicou, na Revista Brasileira de Saúde Mental, um relatório intitulado "20 anos de Terapêutica Ocupacional em Engenho de Dentro", posteriormente transformado em livro, com o título de Terapêutica Ocupacional: teoria e prática. A discussão foi introduzida com uma pesquisa sobre os fundamentos teóricos da Terapêutica Ocupacional, tomando-se por base vários autores, e, em seguida, foram apresentados o histórico e os princípios básicos do trabalho realizado no Centro Psiquiátrico Pedro II.

Nise acreditava que caberia à terapêutica ocupacional parte importante na mudança no ambiente hospitalar e na transformação da própria psiquiatria, desde que as atividades fossem utilizadas com um objetivo clínico, e não para trazer benefícios à instituição, no sentido do desempenho de atividades úteis ao hospital, ou que revertessem em produtos vendáveis. Em suas palavras : "preferimos ajudar nossos doentes antes de pedir-Ihes que ajudem o hospital" (Silveira, s/d, p.24).

Em um amplo sentido, a clínica da terapêutica ocupacional tinha, como objetivo, encontrar atividades que servissem aos doentes como meios de expressão: "será preciso partir do nível não-verbal". É aí que se insere a terapêutica ocupacional, oferecendo atividades que permitam a expressão de vivências não verbalizáveis por aquele que se acha mergulhado na profundeza do inconsciente (Silveira, 1981, p.102).

O interesse da psiquiatra era encontrar o doente, estabelecer com ele algum tipo de relação, abrir-lhe espaço para que ele pudesse dizer sua verdade. Para a autora: "todas as atividades são expressivas. A questão é saber observar como o indivíduo as executa. A maneira como ele empunha o martelo ou a serra, bate o tear, ou, mesmo, parte uma linha de costura, podem exprimir muito" (Silveira, s/d, p.30). Esta ênfase no caráter expressivo das atividades talvez tenha sido o traço que a tenha levado a se aproximar da arte.

Entre as atividades presentes no Setor de Terapêutica Ocupacional, uma, como vimos, chamou a atenção de Nise da Silveira: a pintura. A psiquiatra surpreendeu-se ao constatar que o próprio ato de pintar poderia adquirir, por si mesmo, qualidades terapêuticas. Para ela: 


\section{ESPAÇO ABERTO}

As imagens do inconsciente, objetivadas na pintura, tornavam-se passíveis de certa forma de trato, mesmo sem que houvesse nítida tomada de consciência de suas significações profundas. Lidando com elas, plasmandoas com suas próprias mãos, o doente as via, agora, menos apavorantes e, mais tarde, até inofensivas. Ficavam despojadas de suas fortes e desintegrantes cargas energéticas. (Silveira, s/d, p.32)

Assim, a pintura revelava que o mundo interno do psicótico podia tomar forma se encontrasse meios de expressão que o aproximassem cada vez mais do consciente, passando a ser vista como um instrumento a ser utilizado pelo paciente para reorganizar seu mundo interno e, ao mesmo tempo, reconstruir sua relação com a realidade exterior. Para compreender esse fenômeno, a psiquiatra recorreu à psicologia junguiana e sua concepção de símbolo como mecanismo psicológico que transforma a energia psíquica.

A presença de imagens de grande harmonia na produção plástica dos pacientes chamou a atenção da psiquiatra; estas eram construídas em torno de um centro e figuras que se ligavam de alguma forma a mitos ancestrais. Motivada por essas imagens, estabeleceu uma correspondência com Jung com o intuito de discutir seus significados. Jung the respondeu que algumas daquelas imagens eram mandalas, indicando uma tendência inconsciente a compensar o caos interior e buscar um ponto central, na psique, como tentativa de reconstruir a personalidade dividida. Para ele, a mandala servia a um propósito conservador, sendo uma forma de restabelecimento de uma ordem preexistente. Mas esse símbolo "serve também ao propósito criador de dar forma e expressão a alguma coisa que ainda não existe, algo de novo e único" (Franz, 1987, p.225).

Para Nise da Silveira, o mais importante acontecimento ocorrido nas suas buscas sobre os dinamismos da psique foi o encontro com a psicologia junguiana e seu método de investigação. Foi por intermédio da observação das atividades de seus pacientes que Nise rompeu com a psiquiatria clássica e Jung ofereceu-lhe novos instrumentos de trabalho.

As idéias de Jung acerca da dinâmica dos fenômenos mentais aproximam-se bastante da concepção sistêmica. Jung concebia a psique como um sistema dinâmico autoregulador, caracterizado por flutuações entre pólos opostos. Desse modo, considerava o processo psíquico um processo vital, uma manifestação do dinamismo básico da vida.

Um outro pressuposto presente na psicologia junguiana, que orientou o pensamento e a prática de Nise, refere-se ao conceito de realidade, considerada por Jung como a reunião de fenômenos externos e internos, racionais e irracionais, que compreende unicamente os dados fornecidos pelos sentidos de modo direto e indireto, e compõe, assim, uma totalidade em si. Para ele, o inconsciente humano é uma parte da natureza, é algo objetivo, real, genuíno: "os produtos da atividade do inconsciente merecem o maior crédito, pois são manifestações espontâneas de uma esfera psíquica não controlada pelo consciente, livres em sua forma de expressão" (Silveira, 1992, p.158).

Jung reconhecia os aspectos de natureza pessoal presentes no inconsciente, mas acreditava que o inconsciente trazia consigo um estrato mais profundo da psique, comum a toda a humanidade. Distinguia, portanto, duas esferas na psique inconsciente: um inconsciente pessoal relacionado à história pessoal de cada indivíduo, e um inconsciente coletivo, que compõe um elo e um vínculo ente o indivíduo e a humanidade. Os estratos mais profundos do inconsciente permitiriam o reconhecimento da existência de:

disposições funcionais herdadas inerentes à própria estrutura psíquica, matizes onde tomam forma representações correspondentes a experiências primordiais da humanidade, movidas sob aspectos diferentes pelo homem de todos os tempos. (Silveira apud Frayze-Pereira, 1995, p.94) 
Mediante observações e investigação de natureza mitológica e histórica, Jung nos atualizou sobre a importância dos símbolos elaborados no inconsciente e reconheceu, na produção de imagens, nas fantasias e nos delírios, sua expressão. Para ele, somente pela forma de imagens, a libido pode ser apreendida viva, e não esfiapada pelo repuxamento das tentativas de interpretações racionais. A psique exprime-se em forma de imagens, de afetos e de idéias que condensam intensas experiências da humanidade. Assim, segundo Jung, para conhecermos e entendermos a organização psíquica da personalidade global de uma pessoa, é importante avaliarmos os sonhos e as imagens simbólicas, que nos guiam na descoberta do inconsciente e que, além de apresentarem memórias do passado longínquo, também contêm elementos inteiramente novos e idéias criadoras de novas proposições para as pessoas e para toda a humanidade.

Capra (1988) ressalta que a idéia de inconsciente coletivo de Jung não só liga o indivíduo a toda humanidade como, também, ao cosmo inteiro. Neste sentido nós, seres humanos, somos inextricavelmente ligados àquilo que nos ultrapassa: para além da história pessoal, a rede afetiva e o conjunto de laços que nos unem ao mundo, associamse às forças do cosmos, tornando-nos extremamente complexos. Esta concepção forneceu um lugar de vanguarda na ciência contemporânea.

Nise acreditava que, para acompanhar a produção criativa dos pacientes, era preciso ter paciência e tato, e não apressar as coisas. Em sua experiência, a psicologia junguiana, literatura, arte, e mitologia instrumentalizaram-na para a compreensão das metamorfoses do ser e para a investigação da incansável trajetória do homem em busca do seu mito. Com esses estudos, Nise apresentou uma compreensão da psique como um sistema vivo, com um dinamismo próprio, que se auto-regula e se direciona para a cura e para a saúde. Além disso, criou, ainda, um método para a leitura das imagens que emergiam na produção artísticas dos pacientes que participavam dos ateliês de pintura e modelagem do Setor de Terapia Ocupacional do Engenho de Dentro. O que Nise propõe, num percurso que vai do psíquico ao artístico, não é apenas uma leitura arquetípica das produções artísticas, embora ela seja predominante, mas também uma leitura do psíquico pelos mecanismos de constituição da arte. Segundo a autora, "a vontade de formar o mundo é muito mais profunda nas expressões do inconsciente" (Frayze-Pereira, 1995, p.15).

Nas leituras de seus livros Imagens do Inconsciente e O mundo das Imagens, verificamos que seu modo de trabalhar pressupõe estudos associados à experiência sensível de alguém que se deixou afetar pela observação clínica cuidadosa, articulada ao esforço do pensamento e da reflexão.

O desenvolvimento de um método de leitura de imagens, utilizado no Museu de Imagens do Inconsciente, introduziu uma novidade na forma como, até então, a psiquiatria e, mesmo, a psicanálise tinham tomado as produções de pacientes psicóticos. Nise afirmava que "era forçoso reconhecer que a produção plástica dos psicóticos ia além das representações distorcidas e veladas dos conteúdos pessoais reprimidos (...) Uma pintura quase nunca será o mero reflexo de sintomas" (Silveira, 1981, p.51). Esse método ultrapassa o registro de sintomas, entendendo que, ao pintar, o indivíduo não somente expressa a si mesmo, mas cria algo novo, produz um símbolo, e essa produção tem efeitos de transformação tanto na realidade psíquica como na realidade compartilhada.

A leitura da obra proposta por Nise e realizada na organização das produções artísticas do Museu incorporou-se à história dessas produções e tornou-se parte constitutiva dessas, instaurando um trabalho concreto de reflexão sobre elas. Ao estudarmos as leituras propostas, adentramos a uma densidade do campo simbólico formado pelo trabalho da psiquiatra e pelas criações dos autores que ela acompanhou com tanta dedicação. Para Frayze-Pereira (1995, p.106), a leitura da obra é: "trabalho, e não deciframento, é instauração do sentido, e não mero desvendamento de um significado que se crê já depositado em si mesmo na obra".

No âmbito das relações complexas entre arte e leitura da obra, podemos dizer que a 
proposta de Nise gerou uma ampliação da compreensão das obras produzidas no interno de sua atividade clínica. O cuidado e a delicadeza na organização e manutenção dessas produções favoreceram uma contemplação que, além de transcender a clínica, presenteou, por meio de exposições artísticas, o público mais amplo, abrindo um percurso dessas produções em nossa cultura. Esses gestos criaram, de forma sadia, um caminho de reconhecimento dessas produções e uma experiência sensível no âmbito coletivo que multiplica as formas de compreensão e os pontos de vista desta análise: "Visível-invisível, a obra será sempre uma transcendência em relação ao conhecimento que dela pode vir a ter" (Frayze-Pereira, 1995, p.102).

Podemos pensar, ainda, que o trabalho clínico e teórico realizado por Nise viria transformar, também, as concepções e práticas clínicas que passariam a abordar a ação e a criação como elementos constitutivos da experiência de estar vivo, independentemente do comprometimento psíquico e do tempo da "doença". Sua atenção na construção de ambientes propícios à criação fez com que trabalhasse, também, sobre a organização dos espaços e tempos institucionais e, sobretudo, na formação dos profissionais que com ela acompanhavam pacientes. Para ela, para que qualquer atividade viesse a ter uma função terapêutica, era preciso que fosse desenvolvida num ambiente de ateliê acolhedor que, se diferenciando do ambiente hospitalar no qual estivesse inserido, transformava-se em espaço significativo, desencadeador de aproximações e contatos disruptores do processo de criação. Esses ateliês eram preparados pelos monitores, de forma a dar continência aos internos, acolhendo dores, silêncios, ritmos, e, ao mesmo tempo, estimulando a expressão.

A presença constante de um monitor visava, não a interferência nos trabalho dos pacientes, mas a oferta de um afeto catalisador que pudesse estimular a criatividade e permitisse restaurar pontes de comunicação com o mundo no qual viviam. Nise utilizou o conceito de afeto de Spinosa, como um afeto que seria produzido por um bom encontro, e o associou à idéia de um disparador do processo de cura - tomando a idéia de catalisador da química, ou seja, substâncias cuja presença acelera a velocidade das reações. Acreditava que o processo terapêutico deveria ser acompanhado de forma adequada, cuidadosa e atenta, com a presença e sensibilidade humana para perceber e observar as expressões e manifestações dos pacientes, fundamentais para dar continência às experiências, para não apressar as coisas e para estimular processos de criação, que só poderiam se desenvolver se, no ambiente em que o paciente vivesse, ele encontrasse o suporte do afeto. Dizia ela, "dificilmente qualquer tratamento será eficaz se o doente não tiver ao seu lado alguém que represente um ponto de apoio no qual ele faça investimento afetivo" (Silveira, 1981, p.68).

Neste sentido, valorizava a pessoa humana do monitor, sua sensibilidade e intuição, que favoreceriam uma experiência artística potente. No entanto, mesmo considerando que as teorias valem menos que "o esforço impregnado de simpatia para penetrar no mundo interior do doente" (Silveira, s/d, p.18), a formação do monitor foi sempre uma questão fundamental para Nise da Silveira. Organizou vários cursos para os monitores que trabalhavam nos ateliês. Para ela, essa formação deveria ser contínua, compreendendo conhecimentos em várias áreas, da psiquiatria e psicologia à mitologia, arte e antropologia. O objetivo era que os monitores pudessem compreender o processo psicótico, o processo de cura posto em marcha pela atividade artística, e pudessem fazer conexões entre as imagens produzidas, a situação emocional do interno e as produções culturais de outras épocas e outros lugares, por meio do estudo de séries de imagens. Nise formou profissionais de diversas áreas do conhecimento, efetivando uma experiência interdisciplinar.

Em sua prática psiquiátrica, um outro aspecto a preocupava: as inúmeras reinternações dos pacientes indicavam a necessidade de que o tratamento oferecesse um melhor preparo ao indivíduo que vivenciou a experiência da crise psicótica. Durante anos, Nise pensou sobre a importância de criar uma instituição que estabelecesse uma ponte 
entre o hospital psiquiátrico e a vida em sociedade. Impulsionada pela vontade de proporcionar melhores condições de atendimento ao paciente psiquiátrico, criou a Casa das Palmeiras, fundada em 1956, exemplo precursor de passagem indispensável entre o hospital psiquiátrico e o meio social. O principal método empregado na Casa das Palmeiras foi terapia ocupacional, realizada, segundo Nise, num amplo sentido e com uma nova denominação. A Casa representou um degrau intermediário entre a rotina do sistema hospitalar, desindividualizada, e a vida na sociedade e na família, com seus inevitáveis e múltiplos problemas, onde a aceitação do egresso não se faz sem dificuldade. Num ato de liberdade, preferiram utilizar o termo "a emoção de lidar" para renomear a Terapia Ocupacional que se desenvolveu no trabalho da Casa e, como diz a autora:

Nesse sentido, visamos coordenar intimamente olho e mão, sentimento e pensamento, corpo e psique, primeiro passo para a realização do todo específico que deverá vir a ser a personalidade de cada indivíduo sadio. $\mathrm{Na}$ busca de conseguir esta coordenação, fazemos apelo às atividades que envolvam a função criadora existente, mais ou menos adormecida, dentro de todo indivíduo. (Silveira, 1986, p.11)

\section{Considerações finais}

O trabalho de Nise da Silveira, de grande sensibilidade e delicadeza, abriu espaço para manifestações e criações "loucas" e afirmou a importância de uma escuta atenta e interessada por essas produções. Introduziu uma outra lógica no atendimento de psicóticos, gerando conflito no espaço asilar e fora dele, e provocando um profundo processo de resistência, inovação e transformação cultural. Ao deslocar a ênfase da psiquiatria hegemônica para a terapia ocupacional, fez deslocar, também, o foco principal das pesquisas no campo entre arte e loucura, da investigação psicopatológica e sintomatógica das produções dos doentes, para a construção de um método de tratamento para pacientes internos, e para a pesquisa em torno desse método e seus efeitos.

Assim, a questão terapêutica ganhou um lugar de relevância, chegando a superar a importância da função diagnóstica. A inovação clínica deu-se pela experimentação, invenção, criatividade, pelo afeto, cuidado, pela compreensão e construção de passagens para a autonomia. Jung, ao visitar a exposição do Centro Psiquiátrico Nacional, em Zurique, em 1957, apontava para a diferença desses trabalhos em relação a outras coleções de hospitais psiquiátricos, porque apresentavam harmonia de formas e de cores o que, segundo ele, não era habitual na pintura dos esquizofrênicos, e perguntava sobre a qualidade do ambiente no qual esses doentes pintavam. Mário Pedrosa parece responder a esta pergunta quando diz:

A primeira coisa a constatar [nesses artistas] - com mais ou menos talento, mais ou menos atacados na enfermidade - é que nenhum poderia ser o que são ou que foram no isolamento (...) Na solidão, poderiam qualquer deles ter sido simplesmente destruídos pela vida. A sociedade de Engenho de Dentro, com toda a precariedade de seus recursos, Ihes deu âncora à vida.

(Pedrosa, 1980, p.11)

$\mathrm{Na}$ atmosfera criativa dos espaços de trabalho de Nise da Silveira, havia o cuidado para que o apoio emocional estivesse presente, potencializado, também, com a presença de artistas e de outros profissionais que a auxiliaram a articular as produções do ateliê ao circuito artístico mais amplo, envolvendo públicos mais abrangentes na apreciação das obras, proporcionando uma nova experiência estética para a subjetividade brasileira.

Sua trajetória de vida foi marcada por ações de vanguarda, ocorridas 
aproximadamente quarenta anos antes do início da Reforma Psiquiátrica Brasileira. Suas ações configuraram-se como crítica e resistência à hegemonia da psiquiatria de sua época. Para garantir transformações fundamentais à vida dos pacientes atendidos, lançou-se a estudos e pesquisas inéditos, consistentes, e proporcionou à terapia ocupacional brasileira um campo de fundamentação teórica e clínica, para o qual apresentou uma orientação própria, registrando os resultados obtidos e observados, comprovando aspectos do tratamento, organizando e cuidando das capacidades criativas e artísticas dos loucos.

Seu trabalho e obra caracterizaram uma união com sua vida e engendraram uma verdadeira reinvenção cultural. Num aprofundamento consistente, buscou articular várias áreas do conhecimento para a compreensão de estados existenciais do ser humano, cuja compreensão foi ampliada e a inteligibilidade do mundo redimensionada. Nos estudos e nas aproximações com a vida e a obra de Nise, identificamos uma proposição que apresenta ressonâncias com o desenvolvimento científico contemporâneo, pois os pilares e as expansões de sua obra sustentam um entendimento do homem em sua universalidade e em sua diversidade, simultaneamente. E conduzem, como nas palavras de Morin (1998), a uma possibilidade de redefinição dos laços sociais, a um retorno ao sujeito, à valorização da ética, ao redimensionamento do imaginário e a uma abertura da razão.

Nos dias atuais, a obra de Nise reflete a maturidade de quem, no emaranhado científico de nossa época, pôde manter vivo o espírito, com princípio e horizonte abertos, observando e pesquisando incansavelmente. Ressonâncias sentidas na contemporaneidade: as obras produzidas na interface da Arte e Promoção da Saúde relacionam-se à construção da acessibilidade à ação e criação no mundo de populações, grupos e sujeitos que estão à margem das experiências socioculturais; e, no ato da produção artística, articulam fragmentos de histórias vividas a momentos criativos, dando origem a uma extensa produção que imprime transformações singulares às suas vidas; são experiências que promovem um círculo comunicacional, capacitam lingüisticamente e inserem os sujeitos num campo de inventividade cotidiana. O que Nise realizou é referência para práticas atuais. Sua história produziu, na terapia ocupacional contemporânea, um contágio que faz com que a continuidade da ação permaneça, mesmo que a presença física tenha deixado de existir. A partir dela, arte, cultura e loucura ganharam definitivamente novos sentidos e novas significações.

\section{Referências}

CANCINO, C.A. Imagens do inconsciente. Folha de São Paulo, São Paulo, 12 nov. 1999. Ilustrada, p.E4.

CAPRA, F. O ponto de mutação. São Paulo: Cultrix, 1988.

FRANZ, M.L. O processo de individuação. In: JUNG, C.G. (Org.). O homem e seus símbolos. Rio de Janeiro: Nova Fronteira, 1987. p.158-229.

FRAYZE-PEREIRA, J.A. Olho d'água: arte e loucura em exposição. São Paulo: Escuta \& Fapesp, 1995.

GULLAR, F. Nise da Silveira: uma psiquiatra rebelde. Rio de Janeiro: Relume-Dumará, 1996.

MAVIGNIER, A. O início do ateliê de pintura. In: AGUILAR, N. (Org.). Imagens do inconsciente: mostra do redescobrimento. São Paulo: Associação Brasil 500 anos Artes Visuais, 2000. (Catálogo Fundação Bienal de São Paulo). p.247-9. 
MORIN, E. A ética do sujeito responsável. In: CARVALHO, E.A. (Org.). Ética, solidariedade e complexidade. São Paulo: Palas Athena, 1998. p.65-77.

PEDROSA, M. A Bienal de cá pra lá. In: ARANTES, O.B.F. (Org.). Política das artes: textos escolhidos I. São Paulo: Edusp. 1995. p.217-83.

Museu de imagens do inconsciente. Introdução. Rio de Janeiro: MEC/Funarte, 1980. (Coleção Museus Brasileiros, 2).

QUINET, A. Arte virgem: a função da pintura na psicose. In: QUINET, A. Teoria e clínica da psicose. Rio de Janeiro: Forense Universitária, 2000. p.209-19.

SILVEIRA, N. Imagens do inconsciente. Rio de Janeiro: Alhambra, 1981.

Casa das Palmeiras: a emoção de lidar. Rio de Janeiro: Alhambra, 1986.

O mundo das imagens. São Paulo: Ática, 1992.

Terapêutica ocupacional: teoria e prática. Rio de Janeiro: Casa das Palmeiras, s/d. 
No decorrer da década de 1940, a psiquiatria hegemônica brasileira voltou-se para inovações científicas e tecnológicas e para a sedimentação de uma visão orgânica da doença mental. Nesse contexto, Nise da Silveira pesquisou o desenvolvimento de uma prática clínica em terapia ocupacional, examinando os resultados com inteligência livre de enquadramentos limitadores. Organizou e cuidou dos espaços e tempos para o desenvolvimento das capacidades criativas, da experimentação e do aprendizado artístico dos loucos. Devido à quantidade de desenhos e pinturas e à qualidade das obras produzidas, seus ateliês adquiriram e aglutinaram grande interesse científico e artístico. O trabalho de Nise da Silveira produziu um deslocamento nas atividades realizadas como ocupações monótonas e repetitivas, mantenedoras da lógica asilar; aproximou-as das necessidades reais dos pacientes, abrindo novas possibilidades de ação e participação no mundo para essas pessoas. Sua história é referência para práticas atuais na terapia ocupacional. A partir dela arte, cultura e loucura ganham novos sentidos.

PALAVRAS-CHAVE: Terapia ocupacional. Saúde mental. Arte. Loucura.

\section{Resistance, innovation and clinical practice in Nise da Silveira's thoughts and actions}

In the 40s, hegemonic psychiatry in Brazil turned to scientific and technological innovations and the consolidation of an organic vision of mental illness. Within this context, Nise da Silveira researched the development of clinical practice in the field of occupational therapy and analyzed results with an open mind. She organized and cared for the arenas and time required for developing the creative capacities, experimentation and artistic learning of the mentally ill. The high number and quality of the drawings and paintings produced in her studios have triggered intense scientific and artistic interest. Her work changed the monotonous and repetitive activities conducted within the framework of a mental hospital, bringing them closer to patients' actual needs and creating new possibilities of activity and participation in the world. Her work is a benchmark reference for current practices in occupational therapy. Art, culture and madness acquired new meanings after her.

KEY WORDS: Occupation therapy. Mental health. Art. Madness.

\section{Resistencia, innovación y clínica en el pensamiento y la acción de Nise da Silveira}

En la década de 1940, la psiquiatría hegemónica en Brasil incorporó innovaciones científicas y tecnológicas, consolidando una visión orgánica de la enfermedad mental. En dicho contexto, Nise da Silveira desarrolló una práctica clínica en terapia ocupacional con una inteligencia libre de encasillamientos. Organizó los espacios y tiempos necesarios para el desarrollo de las capacidades creativas, la experimentación y el aprendizaje artístico de los locos. Sus talleres, por la profusión y calidad de dibujos y pinturas que producían, adquirieron un enorme interés científico y artístico. El trabajo de Nise da Silveira produjo un desplazamiento en actividades monótonas, repetitivas y mantenedoras de la lógica asilar, para acercarlas a las reales necesidades de los pacientes, abriéndoles así nuevas posibilidades de acción y participación en el mundo. Su historia constituye una referencia para las actuales prácticas de terapia ocupacional. A partir de Nise da Silveira, el arte, la cultura y la locura adquieren nuevos sentidos.

PALABRAS CLAVE: Terapia ocupacional. Salud mental. Arte. Locura. 